\title{
SEM and X-Ray Diffraction Studies on Microstructures in $\mathrm{Cu}-26.04 \% \mathrm{Zn}-4.01 \% \mathrm{Al}$ Alloy
}

\author{
E. Aldirmaz ${ }^{a, *}$, H. Celik ${ }^{b}$ And I. AKsoY ${ }^{c}$ \\ ${ }^{a}$ Department of Physics, Faculty of Science and Arts, Amasya University, Ipekkoy, 05000 Amasya, Turkey \\ ${ }^{b}$ Department of Elementary Education, Education Faculty, Kırıkkale University, Yahsihan 71450, Kırıkkale, Turkey \\ ${ }^{c}$ Department of Physics, Science and Arts Faculty of Kırıkale University, Yahsihan 71450, Kırıkkale, Turkey
}

(Received March 14, 2013; in final form April 26, 2013)

Due to fact that $\mathrm{Cu}$-based alloys are very sensitive to the thermal treatments, in scanning electron microscopy and X-ray diffraction observations, according to the different quenching techniques $\mathrm{Cu}-26.04 \% \mathrm{Zn}-4.01 \% \mathrm{Al}$ alloys can display different product phases such as martensite and precipitation. Rapidly cooling sample was formed as M18R structure from the ordered $\mathrm{DO}_{3}$ phase and in the monoclinic case, $\beta=89.1^{\circ}$ determined for sample. It was seen that a $\alpha$-precipitation (fcc) phase in the matrix is slowly cooling.

DOI: 10.12693/APhysPolA.124.87

PACS: 61.66.Dk, 07.85.Nc, 61.05.cp, 68.37.Hk, 81.10.Aj

\section{Introduction}

Because of copper-based shape memory alloys have a good shape memory effect, they indicates the advantage of a lower price than $\mathrm{Ni}-\mathrm{Ti}$ shape memory alloys [1]. Copper-based shape memory alloys are very sensitive to the thermal effects before and after the transformation. Therefore these effects may cause important changes on crystallographic properties or the other transformation parameters of the alloys [2]. Cu-based shape memory $\beta$-phase alloys exhibit order-disorder transformation at elevated temperatures. Although the $\beta_{1}$-phase is metastable, it remains stable at room temperature upon quenching from the high temperature $\beta$-phase [3]. Metastable parent $\beta_{1}\left(\mathrm{~B} 2\right.$ or $\left.\mathrm{DO}_{3}\right)$ and martensitic $\beta_{1}^{\prime}$ (M9R or M18R) phases are transformed to bainitic $\alpha_{1}$ (9R), complex cubic $\gamma_{2}$, or fcc $\alpha$ phases by thermally activated processes [4-6]. In the majority of copper-based alloys such as $\mathrm{Cu}-\mathrm{Zn}-\mathrm{Al}$ the bainitic precipitation has been observed. Bainitic transformation occurs in these copper-based alloys, and $\beta$-phase forms diffusionally [7]. Since it has a diffusionless nucleation and a diffusion-controlled growth, even so its formation is accompanied by a geometry change characterized as reverse shape memory effect, bainitic transformation is irreversible, in contrast to martensitic transformation [8].

Among various $\mathrm{Cu}$-based ternary shape memory alloys (SMAs), single crystals of $\mathrm{Cu}-\mathrm{Zn}-\mathrm{Al}, \mathrm{Cu}-\mathrm{Al}-\mathrm{Ni}$ and $\mathrm{Cu}-\mathrm{Al}-\mathrm{Mn}$ alloys were most thoroughly investigated. Although there are many studies reporting some physical properties of copper-based alloys, literature reveals no studies on the effects of thermal on microstructure and properties of microstructures for the related composition of alloys. In our study microstructures of martensites and

*corresponding author; e-mail: ealdirmaz@gmail.com precipitates formation in the related alloys were reported in detail.

\section{Experimental details}

The composition of the alloy used in the present study was $\mathrm{Cu}-26.04 \% \mathrm{Zn}-4.01 \% \mathrm{Al}$ (wt\%) which were prepared by vacuum induction melting under an argon atmosphere from pure (99.9\%) alloying elements. After this alloying, product alloy was used in the form of cylindrical bars with $1 \mathrm{~cm}$ diameter and $10 \mathrm{~cm}$ length. Samples cut from the alloy were heated in evacuated quartz tubes in an $\mathrm{Ar}$ atmosphere and immediately quenched into iced-brine rapidly cooling or in furnace cooled slowly cooling for homogenization. First group of samples were homogenized at $850^{\circ} \mathrm{C}$ for $30 \mathrm{~min}$ and quenched into iced-brine water (sample $A$ ), the second group of samples were homogenized at $850^{\circ} \mathrm{C}$ for $30 \mathrm{~min}$ and furnace cooled to $25^{\circ} \mathrm{C}$ at a rate of approximately $2{ }^{\circ} \mathrm{C} / \mathrm{min}$ and then air cooled (sample B). Bulk samples used in the scanning electron microscopy (SEM) observations were mechanically polished and etched into a solution composed of $2.5 \mathrm{~g}$ $\mathrm{FeCl}_{3} \cdot 6 \mathrm{H}_{2} \mathrm{O}$ and $48 \mathrm{ml}$ methanol in $10 \mathrm{ml} \mathrm{HCl}$. SEM observations were made under a JEOL 5600 scanning microscope operated at $20 \mathrm{kV}$. X-ray diffraction patterns of the powder samples were taken by a Bruker D8 Advance diffractrometer. For these examinations, the monochromatic copper $K_{\alpha}$ radiation with wavelength of $1.5418 \AA$ was used, a step size of $0.02^{\circ}$.

\section{Results and discussion}

The microstructures of the sample $A$ that were quenched directly into iced-brine water are shown in Fig. 1a-c. The sample that were quenched into iced-brine water show a microstructure that is fully martensitic. Martensites appear to the typical morphology of $\beta_{1}^{\prime}$ martensite. Martensite plates are formed in a V-shape 
in some grains while they occur needle-like in others (Fig. 1a) [9]. This kind of needle-like martensite in $\mathrm{Cu}-\mathrm{Zn}-\mathrm{Al}$ alloy has been reported until now (Fig. 1b) [2]. As seen from Fig. 1c SEM micrograph shows selfaccommodating martensite plate groups. The fundamental grade of the shape memory effect can be illustrated by self-accommodation mechanism. Self-accommodating martensitic transformation involves plate groups, and each of them contains four "cooperating" martensite variants [10, 11]. Figure 1d shows $\alpha$-precipitation (fcc) phase in the matrix, the morphological structures about surface observation which has got over by cooling gradually $\mathrm{Cu}-\mathrm{Zn}-\mathrm{Al}$ shape memory alloy (sample $B$ ). The precipitation kinetics of $\mathrm{Cu}-\mathrm{Zn}-\mathrm{Al}$ alloys are very sensitive to zinc and aluminum content. Moreover, the precipitation of $\alpha$ or other phases causes a degradation in the shape memory capability and decreases of the forward-transformation temperatures. This effect is related to the interaction of martensite interfaces with the precipitates and defects. Decrease of aluminum content in shape memory $\mathrm{Cu}-\mathrm{Zn}-\mathrm{Al}$ alloys accelerates the formation of both $\alpha$ and $\alpha_{1}$ phases. The high shape-memory life of $\mathrm{Cu}-\mathrm{Zn}-\mathrm{Al}$ alloys at high temperatures can be obtained by increasing the $\mathrm{Al}$ content. These results are in agreement with the observations made previously [12-14].
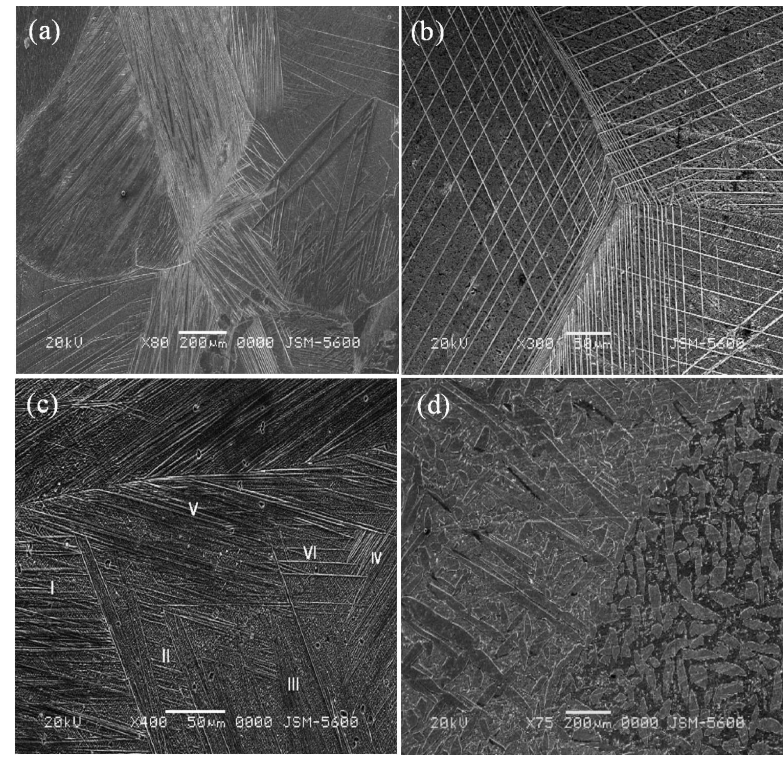

Fig. 1. SEM micrographs showing the microstructures of the alloy 2: (a) $V$-type and needle-like martensites in different grain, (b) needle-like martensites, (c) $\beta_{1}^{\prime}$ martensite self-accommodating variants, and (d) $\alpha$ precipitates in parent phase.

In order to determine the crystal structure of the $\mathrm{Cu}-\mathrm{Al}-\mathrm{Zn}$ alloys in the martensitic state, X-ray diffraction (XRD) samples were taken. Typical X-ray powder diffraction profiles taken from the samples of alloy are shown in Fig. 2. The measured $d$ values $\left(d_{\mathrm{m}}\right)$ of each diffraction peak, its relative integrated intensities and $h k l$ planes measured are shown in Tables I and II, respec-

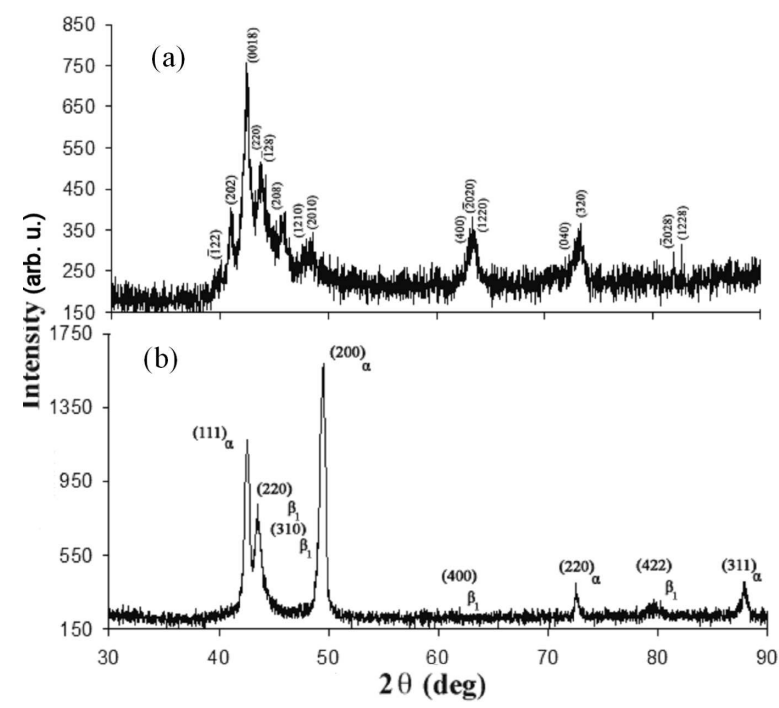

Fig. 2. X-ray powder diffractograms of the samples of alloy: (a) sample $A$, (b) sample $B$.

tively, for sample $A$ and $B$. As seen from these diffractograms, the alloys exhibit superlattice reflections in the quenched case. Sample $A$, only $\beta_{1}^{\prime}$ martensite is formed, $\gamma_{1}^{\prime}$ martensite phase was not detected (Fig. 2a).

TABLE I

The values of the $2 \theta$ angles, intensities of X-ray diffraction and the Miller indices of the crystal lattice planes that contribute to the X-ray peaks for sample $A$.

\begin{tabular}{|c|c|c|c|c|c|c|c|}
\hline \multicolumn{2}{|c|}{$2 \theta\left[^{\circ}\right]$} & \multicolumn{2}{|c|}{$d[\AA]$} & \multicolumn{2}{|c|}{$I / I_{0}$} & \multicolumn{2}{|c|}{$(h k l)$} \\
\hline M18R & $\mathrm{DO}_{3}$ & M18R & $\mathrm{DO}_{3}$ & M18R & $\mathrm{DO}_{3}$ & M18R & $\mathrm{DO}_{3}$ \\
\hline 40.18 & 43.60 & 2.2442 & 2.0758 & 278 & 442 & $(\overline{1} 22)$ & 220 \\
\hline 40.96 & 63.36 & 2.2033 & 1.4679 & 407 & 343 & $(202)$ & 400 \\
\hline 42.44 & & 2.1298 & & 758 & & (0018) & \\
\hline 44.20 & & 2.0490 & & 483 & & $(\overline{1} 28)$ & \\
\hline 45.28 & & 2.0026 & & 373 & & (208) & \\
\hline 46.88 & & 1.9379 & & 285 & & (1210) & \\
\hline 47.64 & & 1.9088 & & 308 & & (2010) & \\
\hline 63.54 & & 1.4462 & & 305 & & $(\overline{2} 020)$ & \\
\hline 64.00 & & 1.4549 & & 285 & & (1220) & \\
\hline 72.10 & & 1.3099 & & 262 & & $(040)$ & \\
\hline 73.42 & & 1.2896 & & 320 & & $(320)$ & \\
\hline 82.00 & & 1.1750 & & 297 & & $(\overline{2} 028)$ & \\
\hline 82.76 & & 1.1662 & & 317 & & (1228) & \\
\hline $\mathrm{DO}_{3}$ & & & & $=5$. & A & & \\
\hline M18R & & 4.445 & 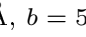 & $10 \AA$ & & 8 & $9.1^{\circ}$ \\
\hline
\end{tabular}

The martensitic phase in copper based $\beta$-phase alloys is based on one of the $\{110\}_{\beta}$ basal planes. In the case where the constituent atoms are randomly distributed in the basal plane, the ratio $a / b$ of the lattices parameters should be equal to $\sqrt{3} / 2$, while the value of this ratio is less than $\sqrt{3} / 2$ in the ordered case due to the atomic sizes of the constituent atoms for $18 \mathrm{R}$ martensite [15-17]. The ratio of $a / b$ for sample $A$ was determined as 0.84 . As a result of this ratio, product martensite with $18 \mathrm{R}$ structure was formed from the ordered $\mathrm{DO}_{3}$ phase [3]. Thus, the sample $A$ has an ordered state inherited from the or- 
TABLE II

The values of the $2 \theta$ angles, intensities of X-ray diffraction and the Miller indices of the crystal lattice planes that contribute to the X-ray peaks for sample $B$.

\begin{tabular}{c|c|c|c|c|c|c|c}
\hline \hline \multicolumn{3}{c|}{$\begin{array}{c}\text { Precipitation-phase } \\
\text { (fcc) } \alpha \text {-phase }\end{array}$} & \multicolumn{4}{c}{$\begin{array}{c}\text { Parent-phase } \\
\text { (bcc) } \beta_{1} \text {-phase }\end{array}$} \\
\hline $2 \theta\left[{ }^{\circ}\right]$ & $d[\AA]$ & $I / I_{0}$ & $(h k l)$ & $2 \theta\left[{ }^{\circ}\right]$ & $d[\AA]$ & $I / I_{0}$ & $(h k l)$ \\
\hline 42.54 & 2.1250 & 1104 & $(111)$ & 43.62 & 2.0749 & 771 & $(220)$ \\
49.54 & 1.8399 & 1479 & $(200)$ & 49.08 & 1.8561 & 625 & $(310)$ \\
72.66 & 1.3012 & 293 & $(220)$ & 63.38 & 1.4675 & 213 & $(400)$ \\
88.02 & 1.1095 & 320 & $(311)$ & 80.08 & 1.1983 & 237 & $(422)$ \\
\hline \multicolumn{3}{c|}{$a=3.68 \AA$} & \multicolumn{5}{c}{$a=5.87 \AA$} \\
\hline
\end{tabular}

dered parent phase existing prior to the transformation. Monoclinic distortion takes place in some cases, and $18 \mathrm{R}$ structure is modified as M18R [15]. The normal structure is orthorombic samples, whereas the modified version is monoclinic [18].

In the monoclinic case, $\beta=89.1^{\circ}$ determined for sample $A$. The deviation observed in the angle is very little and shows that the long range order has a excellent $\mathrm{DO}_{3}$ order. If the monoclinic angle of the quenched martensite, $\beta$, is $90^{\circ}$ (orthorhombic) or very close to $90^{\circ}$, the transition from monoclinic to orthorhombic would be restrained, but it would be difficult for the martensite stabilization to occur during aging in the martensite state, these results are in agreement with the observation made by other work [19]. The lattice parameters calculated from these profiles of sample $A$ were $a=4.43 \AA, b=5.67 \AA$ and $c=4.85 \AA$. XRD observations showed that phase transformation occurred in sample $B$ (Fig. 2b). Figure $2 \mathrm{~b}$ shows that the precipitates are seen that in sample $B$ were observed as $\alpha$-phase. The $\alpha$-phase is the cubic fcc copper-rich solid solution [20]. It was detected as fcc $\alpha$-phase with parameter $a=3.68 \AA$.

Although all of the diffractograms exhibit similar characteristics, some changes have been observed in peak locations on the diffractograms with thermal treatment and the differences in lattice constants [15]. These changes are attributed to new transitions which have diffusive character. It can be explained that some neighbour atoms change locations and also some of the neighbour peak pairs have moved toward each other [21].

\section{Conclusions}

It can be concluded from the above results that the copper based shape memory alloys are very sensitive to the thermal treatments. In the present work, mono- clinic martensitic structure M18R was observed in step-quenched samples of alloy. Direct quenching into an iced-brine water results in the formation of $100 \%$ martensite, whereas quenching into other slowly, such as furnace cooled, results in the conversion of some amount of austenite into $\alpha$ precipitates.

\section{References}

[1] F.J. Gil, J. Pena, J.M. Guillemany, J. Mater. Synth. Proc. 7, 127 (1999).

[2] Ş.N. Balo, M. Ceylan, M. Aksoy, Mater. Sci. Eng. A 311, 151 (2001).

[3] A. Aydoğdu, Y. Aydoğdu, O. Adigüzel, Mater. Res. Bull. 32, 507 (1997).

[4] N.F. Kennon, D.P. Dunne, L. Middleton, Metall. Trans. 13A, 551 (1982).

[5] Y.S. Han, Y.G. Kim, J. Mater. Sci. 21, 2711 (1986).

[6] M.M. Reyhani, P.G. McCormick, Scr. Metall. 20, 571 (1986).

[7] Y.S. Han, Y.G. Kim, Scr. Metall. 21, 947 (1987).

[8] H. Pops, in: Shape Memory Effects in Alloys, Ed. J. Perkins, Plenum Press, New York 1975, p. 525.

[9] F. Dagdelen, T. Gokhan, A. Aydogdu, Y. Aydogdu, O. Adiguzel, Mater. Lett. 57, 1079 (2003).

[10] T. Saburi, C.M. Wayman, K. Takata, S. Nenno, Acta Metall. 28, 15 (1980).

[11] T. Saburi, C.M. Wayman, Acta Metall. 27, 979 (1979).

[12] S.S. Leu, C.T. Hu, Metall. Trans. 22A, 25 (1991).

[13] V. Sampath, Mater. Manufac. Proc. 22, 9 (2007).

[14] N.B. Pugacheva, Metal Sci. Heat Treatment 49, 67 (2007).

[15] O. Adıgüzel, Mater. Res. Bull. 30, 755 (1995).

[16] Q. Xuan, J. Bohong, T.Y. Hsu, Mater. Sci. Eng. 93, 205 (1987).

[17] N. Kayali, S. Ozgen, O. Adigüzel, Mater. Res. Bull. 32, 569 (1997).

[18] O. Adıüzel, Commun. Fac. Sci. Ankara, Series A2, A3 36, 47 (1987).

[19] J. Van Humbeeck, M. Chandrasekaran, L. Delay, ISIJ Int. 29, 388 (1989).

[20] J. Hirsch, K. Lucke, M. Hatherly, Acta Metall. 36, 2905 (1988).

[21] O. Adiguzel, J. Mater. Proc. Technol. 185, 120 (2007). 